\title{
Measurement and correlation of excess molar enthalpies and vapor-liquid equilibria for alkanolamine-water system
}

\author{
Ruilei Zhang \\ Institute of Disaster Prevention, School of ecology and environment, Langfang 101601, China
}

Corresponding Author Email: zhangrl420@163.com

https://doi.org/10.18280/ijht.360204

Received: 9 October 2017

Accepted: 27 February 2018

\section{Keywords:}

alkanolamines, vapor-liquid equilibria, NRTL equations, measurement and correlation

\begin{abstract}
The absorption of carbon dioxide by alkanolamine aqueous solution is directly related to its thermodynamic properties, thus the important thermodynamic properties of the system such as vapor-liquid equilibria and excess molar enthalpies must be first determined for the selection of new absorbents with high absorption rate and strong absorption capacity. However, these data on alkanolamine aqueous solution are rarely seen in the literature. Therefore, the present study measures the excess molar enthalpies of 1, 2-diethylaminoethanol and water at 298.15 $\mathrm{K}, 303.15 \mathrm{~K}$ and $323.15 \mathrm{~K}$ in the whole concentration range, using C-80 microcalorimetry, and vapor-liquid equilibria data of the system under the condition of $30-101 \mathrm{kPa}$ using a vaporliquid double circulation device, correlates the calculated excess molar enthalpies and vaporliquid equilibria data using non-random two-fluid NRTL model, and finally provides the model parameters of the equation. The results show that the fitting results of the vapor-liquid equilibria and excess molar enthalpies are in good agreement with the experimental values, which further verifies that the model can be used for the absorption of carbon dioxide by alkanolamine aqueous solution.
\end{abstract}

\section{INTRODUCTION}

Alkanolamine is an important organic chemical product, which is mainly used for natural gas production, fossil fuel combustion and desulfurization and decarbonization in chemical plants. Alkanolamine is currently a commonly used solvent for acid gas removal [1]. As people's awareness of environmental protection increases, more and more studies focus on alkanolamine aqueous solution. Although some studies have been conducted on the absorption of acid gases by alkanolamine, the key of the absorption lies in energy consumption at this stage [2-3]. Therefore, it is necessary to study the thermodynamic properties of solvents to select low energy consumption solvents so that alkanolamine can be more widely used for absorption of acid gas.

The excess molar enthalpies $\mathrm{H}^{\mathrm{E}}$ is an important thermodynamic property of the solution, which reflects the change of the intermolecular interaction force during mixing, and is one of the main signs of the non-ideality of the solution. The significance of measuring excess molar enthalpies lies in the following points. It helps to establish a new theoretical solution model to verify the feasibility of the existing solution theory models, facilitates multi-stage and multi-component equilibrium modeling in absorption/ desorption columns and solubility modeling of gases in alkanolamine aqueous solution, which provides important basis for the design of absorption and desorption equipment, and can also help to calculate other thermodynamic properties. Chang et al. [4] have proved that the activity coefficients of alkanolamine and water have an important effect on predicting the vapor-liquid equilibria of acid gas in this range under lower acid gas loading. In this study, 1, 2-diethylaminoethanol (DEEA) containing branched organic tertiary amine is selected as the research object. As there is no data on the excess molar enthalpies of DEEA and water at present, the excess molar enthalpies of DEEA and water at $298.15 \mathrm{~K}, 303.15 \mathrm{~K}$ and $323.15 \mathrm{~K}$ and the vapor-liquid equilibria data at $30-101 \mathrm{kPa}$ are determined experimentally. On this basis, the thermodynamic model is established by simultaneously fitting the vapor-liquid equilibria data and the excess molar enthalpies.

\section{EXPERIMENTAL DEVICE AND METHOD}

\subsection{Experimental reagents}

Table 1. Purity and source of experimental reagents

\begin{tabular}{ccccc}
\hline Name & $\begin{array}{c}\text { Molecular } \\
\text { formula }\end{array}$ & $\begin{array}{c}\text { Molecular } \\
\text { weight }\end{array}$ & Purity & Source \\
\hline $\begin{array}{c}\text { Deionized water } \\
\mathrm{N}, \mathrm{N}-\end{array}$ & $\mathrm{H}_{2} \mathrm{O}$ & 18.0152 & & $\begin{array}{c}\text { Beijing Jiangchuan Environmental Engineering } \\
\text { Technology Co., Ltd. }\end{array}$ \\
$\begin{array}{c}\text { Diethylethanolamine } \\
\text { Diethanolamine }\end{array}$ & $\begin{array}{c}\left(\mathrm{C}_{2} \mathrm{H}_{5}\right)_{2} \mathrm{NC}_{2} \mathrm{H}_{4} \mathrm{OH} \\
\mathrm{NH}\left(\mathrm{CH}_{2} \mathrm{CH}_{2} \mathrm{OH}\right)_{2}\end{array}$ & 117.2 & $99 \%$ & Texaco Chemical Co., Ltd. Rizhao Power \\
\hline
\end{tabular}


The chemical reagents used in the experiment are shown in Table 1, which are all directly used without further processing or purification.

\subsection{Experimental instrument}

(1) The excess molar enthalpies of the DEEA $+\mathrm{H}_{2} \mathrm{O}$ system is measured using a C-80 calorimeter (shown in Figure 1-a). The working principle of the device is the principle of TianCalvet heat flow.

(2) The vapor-liquid equilibria data at constant pressure are measured using gas-liquid double circulation device [5] (a modified ROSE kettle as shown in Figure 1-b), with an error rate of less than $1 \%$.

(3) The gas and liquid phase composition is determined using Auto-ABEE Model Abbe refractometer with a resolution of 0.000001 .

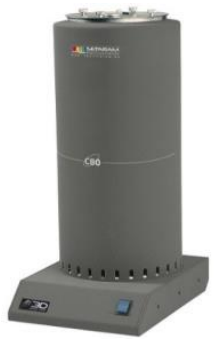

Figure 1-a. C-80 calorimeter

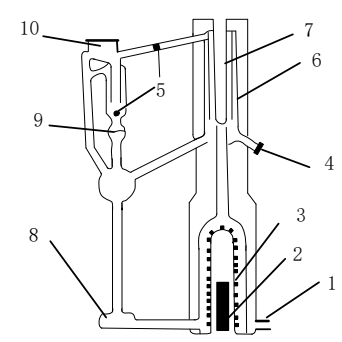

Figure 1-b. Vapor liquid double circulation device

\subsection{Calibration of experimental device}

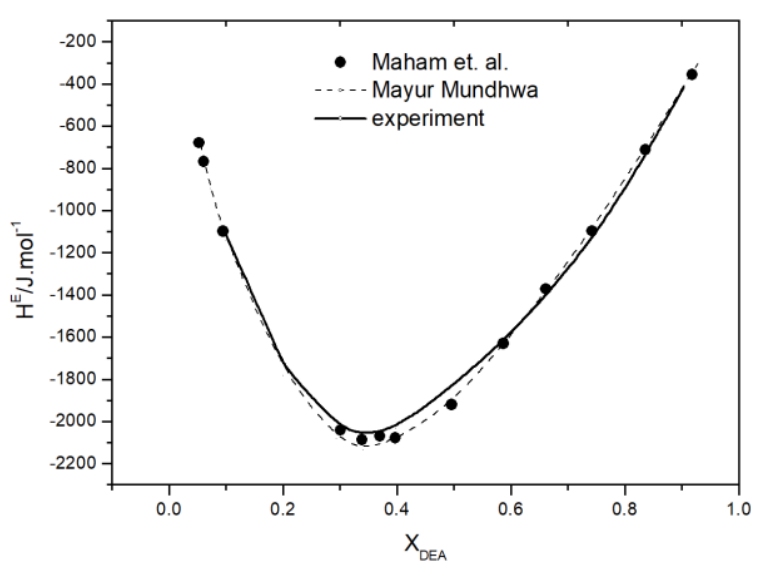

Figure 2. Comparison of DEA $+\mathrm{H}_{2} \mathrm{O}$ excess molar enthalpies values at $298.15 \mathrm{~K}$ in the experiment and that in the literature

To verify the measurement accuracy of the C-80 calorimeter, it is generally possible to use Diethanolamine (DEA) $+\mathrm{H}_{2} \mathrm{O}$ system or $\mathrm{N}$-methyldiethanolamine (MDEA) + $\mathrm{H}_{2} \mathrm{O}$ system as a benchmark system for comparison [6]. The $\mathrm{DEA}+\mathrm{H}_{2} \mathrm{O}$ system is selected for the experiment and its excess molar enthalpies at $298.15 \mathrm{~K}$ is measured. The excess molar enthalpies of the system under the same conditions has been measured by Yadollah Maham[7] and Mayur Mundhwa[8] and is listed in Figure 2 together with the results of this experiment. These two groups of data are in a good coincidence with each other, which proves the high accuracy of the calorimeter used, thus it can be used for the measurement of the new system.

\section{THERMODYNAMIC MODEL AND SELECTION OF OBJECTIVE FUNCTION}

The commonly used solution theory models are local composition models, including NRTL model, Wilson model, UNIQUAC model, and UNIFAC model, in which the NRTL model is simpler in form and more efficient in programming than the UNIFAC model. Some scholars have proved that the NRTL model is superior to the UNIQUAC model in fitting results [9], with a higher accuracy in fitting $\mathrm{H}^{\mathrm{E}}$ data [4]. Moreover, NRTL model can successfully correlate vaporliquid equilibria data and excess molar enthalpies simultaneously [10-13]. Therefore, this study selects the NRTL model for data fitting.

This paper uses both phase equilibrium data and excess molar enthalpies to fit the model parameters, thus they can accurately predict the phase equilibrium and excess molar enthalpies in the appropriate pressure and temperature range. The two most commonly used forms for simultaneous fitting of excess molar enthalpies and vapor-liquid equilibria are as follows:

$$
\begin{aligned}
& F=\frac{1}{N_{p}}\left\{\sum_{i=1}^{N_{p}}\left(p^{\exp }-p^{\text {calc }}\right)_{i}^{2}\right\} \\
& +\frac{1}{M_{p}}\left\{\sum_{i=1}^{M_{p}}\left(H^{E, \exp }-H^{E, \text { calc }}\right)_{i}^{2}\right\} \\
& F=\frac{1}{N_{p}}\left\{\sum_{i=1}^{N_{p}}\left(\frac{p^{\exp }-p^{\text {calc }}}{p^{\exp }}\right)_{i}^{2}\right\} \\
& +\frac{1}{\mathrm{M}_{\mathrm{p}}}\left\{\sum_{i=1}^{M_{p}}\left(\frac{H^{E, \exp }-H^{E, \text { calc }}}{H^{E, \exp }}\right)_{i}^{2}\right\}
\end{aligned}
$$

Table 2. Comparison of errors in two forms of objective functions

\begin{tabular}{ccccc}
\hline System & $\begin{array}{c}\text { Data } \\
\text { type }\end{array}$ & Number & $\begin{array}{c}\text { Absolute } \\
\text { deviation }\end{array}$ & $\begin{array}{c}\text { Relative } \\
\text { deviation }\end{array}$ \\
\hline $\mathrm{MEA}+\mathrm{H}$ & $\mathrm{VLE}$ & 175 & 3.774 & 2.523 \\
${ }_{2} \mathrm{O}$ & $\mathrm{H}^{\mathrm{E}}$ & 52 & 1.095 & 4.845 \\
$\mathrm{MDEA}+$ & $\mathrm{VLE}$ & 59 & 17.931 & 0.436 \\
$\mathrm{H}_{2} \mathrm{O}$ & $\mathrm{H}^{\mathrm{E}}$ & 45 & 4.973 & 5.897 \\
\hline
\end{tabular}

Table 3. Calculation error of the new objective function

\begin{tabular}{ccccc}
\hline System & Data type & $\begin{array}{c}\text { Temperature } \\
\text { range }\end{array}$ & Number & Error \\
\hline $\mathrm{MEA}+$ & $\mathrm{VLE}$ & $10-167^{\circ} \mathrm{C}$ & 175 & 2.411 \\
$\mathrm{H}_{2} \mathrm{O}$ & $\mathrm{H}^{\mathrm{E}}$ & $25^{\circ} \mathrm{C}$ & 52 & 3.571 \\
$\mathrm{MDEA}+\mathrm{H}_{2} \mathrm{O}$ & $\mathrm{VLE}$ & $40-100^{\circ} \mathrm{C}$ & 59 & 0.473 \\
& $\mathrm{H}^{\mathrm{E}}$ & $25-65^{\circ} \mathrm{C}$ & 45 & 5.779 \\
\hline
\end{tabular}

In order to determine the form of the final objective function, the commonly used monoethanolamine (MEA) + $\mathrm{H}_{2} \mathrm{O}$ system [14-17] and MDEA $+\mathrm{H}_{2} \mathrm{O}$ system [7-8, 17-18] are selected from the literature for calculation. As shown by the program running results in Table 2 , the objective function in the form of absolute deviation can well fit the excess molar enthalpies, but the calculated values of the vapor-liquid equilibria data deviate greatly from the experimental values [19]. The objective function in the form of relative deviation 
can well fit the vapor-liquid equilibria data, but there is a big deviation between the calculated value of excess molar enthalpies and the experimental value. A new objective function is established, with the excess molar enthalpies in the form of absolute deviation and the vapor-liquid equilibria data in the form of relative deviation, as shown in Formula (3). The results are shown in Table 3 .

$F=\frac{\gamma_{p}}{N_{p}}\left\{\sum_{i=1}^{N_{p}}\left(\frac{p^{\exp }-p^{c a l c}}{p^{\exp }}\right)_{i}^{2}\right\}$

$+\frac{\gamma_{H^{E}}}{\mathrm{M}_{\mathrm{p}}}\left\{\sum_{i=1}^{M_{p}}\left(\mathrm{H}^{\mathrm{E}, \exp }-\mathrm{H}^{\mathrm{E}, \mathrm{calc}}\right)_{i}^{2}\right\}$

\section{RESULTS AND ANALYSIS}

\subsection{Excess molar enthalpies}

The points in Figure 3 represent the measured excess molar enthalpies of DEEA and water. From the Figure, it can be seen that the heat of mixing is negative, indicating that alkanolamine mixes with water to release heat, which reaches maximum at $\mathrm{x}=0.38$. The heat release is mainly related to the interaction between alkanolamine and water. The interaction between water and amino group in alkanolamine is stronger than that between water and hydroxyl group in alkanolamine, that is, the influence of amino group is stronger than that of hydroxyl group, and the more amino group in alkanolamine, the greater the maximum value of excess molar enthalpies.

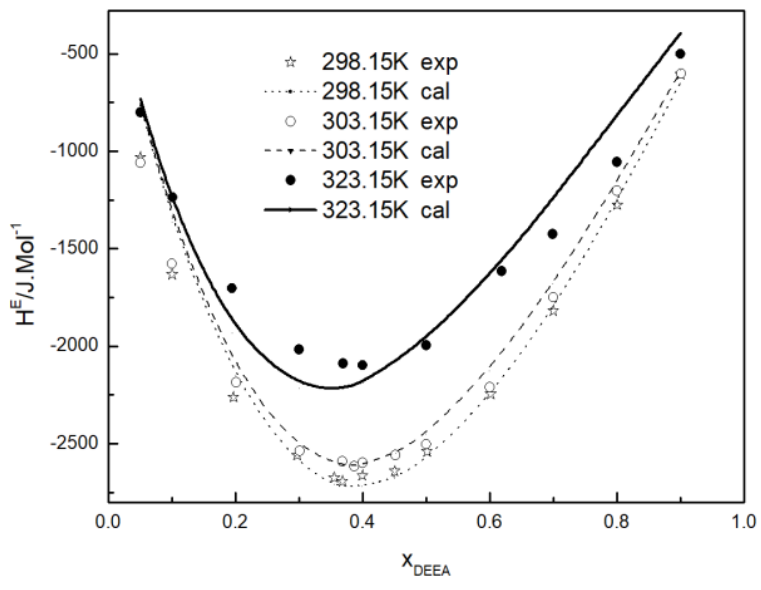

Figure 3. Fitting results of mixed heating data of DEEA + $\mathrm{H}_{2} \mathrm{O}$ system (lines represent calculated value, and points experimental value)

\subsection{Vapor-liquid equilibria data}

In this paper, the vapor-liquid equilibria data of DEEA aqueous solution have been measured by gas-liquid double circulation device. Most amine solutions have strong adsorption, and their polarity of the column is too strong, leading to strong retention of the amine solution. Adding to that, polarity is too weak, thus the water and amine peaks cannot be easily separated. Therefore, this article uses a refractometer for analysis. From the range of $0-1$, the bubble point and the dew point lines are almost in a straight line in the low concentration area, and all the experimental points are on this part of the line. After amplification, the presence of azeotropic points is clearly observed. Therefore, the NRTL equation predicts azeotropic phenomena in low concentration regions.

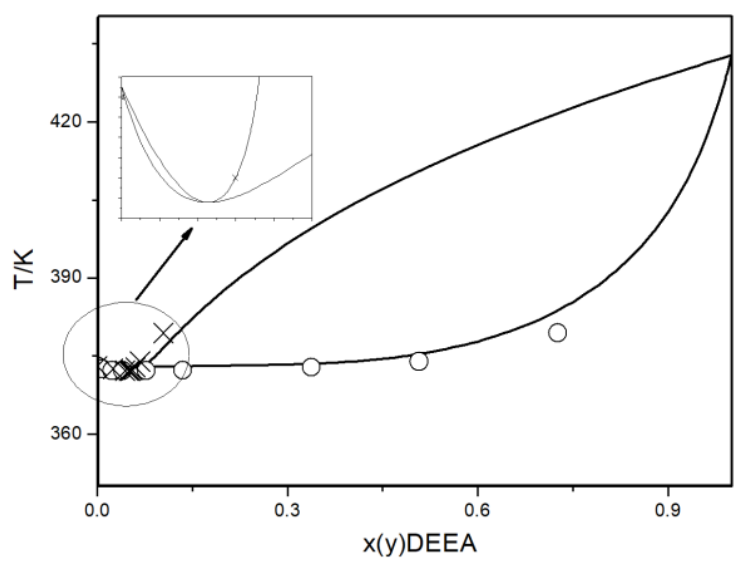

Figure 4. Fitting Results of VLE data of DEEA $+\mathrm{H}_{2} \mathrm{O}$ System at $101.3 \mathrm{kPa}$ (lines represent calculated value, and points experimental value)

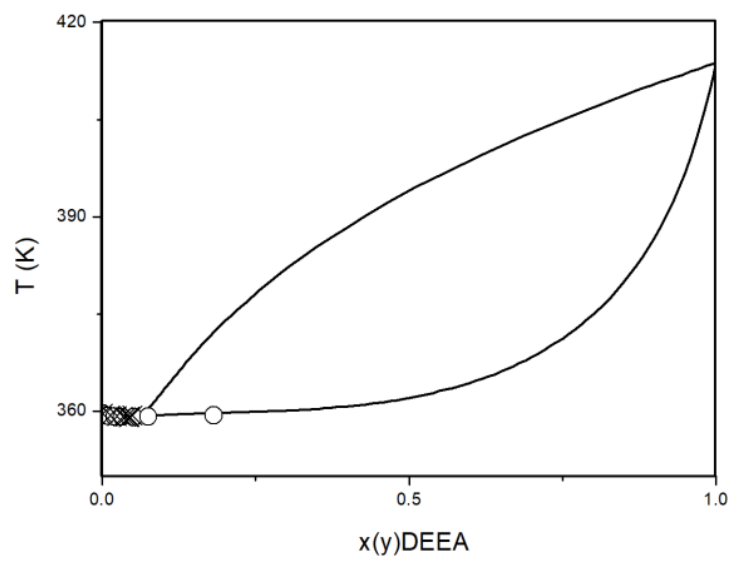

Figure 5. Fitting Results of VLE data of DEEA $+\mathrm{H}_{2} \mathrm{O}$ System at $60 \mathrm{kPa}$ (lines represent calculated value, and points experimental value)

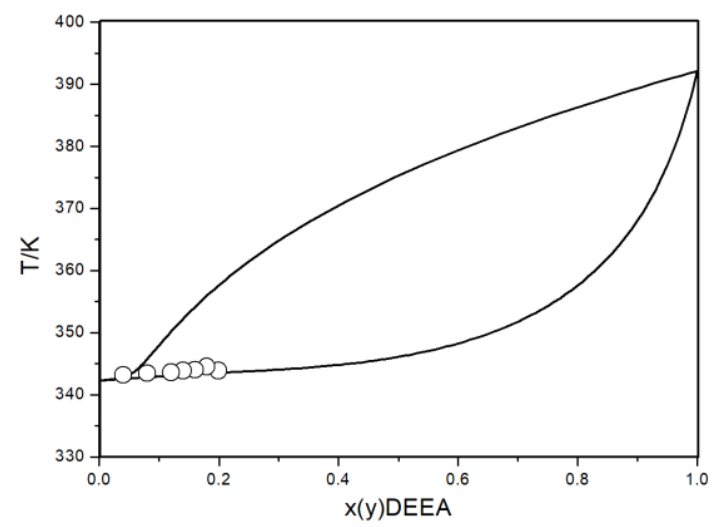

Figure 6. Fitting Results of VLE data of DEEA $+\mathrm{H}_{2} \mathrm{O}$ System at $30 \mathrm{kPa}$ (lines represent calculated value, and points experimental value)

\subsection{Analysis of simultaneous fitting results of NRTL model parameters}

The objective function uses Formula (3) and the NRTL model to simultaneously fit the $H^{E}$ and VLE data obtained in 
the experiment. The fitting results are shown in Figures 3-6. The respective fitting errors are listed in Table 4 and the parameters of the system's NRTL equation in Table 5. The vapor-liquid equilibria data used in the above fitting have been tested for thermodynamic consistency. As can be seen from Table 4, the fitting error of the vapor-liquid equilibria data is small, thus the fitting result can basically represent the experimental results.

Table 4. Error of simultaneous fitting using NRTL equation

\begin{tabular}{ccccc}
\hline System & Data type & Temperature range & Number & Error \\
\hline DEEA $+\mathrm{H}_{2} \mathrm{O}$ & VLE & $334-398$ & 104 & 0.7027 \\
& $\mathrm{H}^{\mathrm{E}}$ & $298,303,323$ & 37 & 6.584 \\
\hline
\end{tabular}

Table 5. Parameters of the equation for simultaneous fitting of NRTL in DEEA $+\mathrm{H}_{2} \mathrm{O}$ System

\begin{tabular}{ccccc}
\hline $\mathrm{a} 12$ & $\mathrm{a} 21$ & $\mathrm{~b} 12 / \mathrm{K}$ & $\mathrm{b} 21 / \mathrm{K}$ & $\alpha$ \\
\hline-1.5905 & 9.8297 & 388.27 & -2441.1 & 0.2 \\
\hline
\end{tabular}

\section{CONCLUSIONS}

In this article, the excess molar enthalpies of DEEA and water at $298.15 \mathrm{~K}, 303.15 \mathrm{~K}$ and $323.15 \mathrm{~K}$ and the vapor-liquid equilibria data at $30-101 \mathrm{kPa}$ are measured. Based on these experimental data, the thermodynamic model is established by simultaneously fitting the vapor-liquid equilibria data and the excess molar enthalpies, and the relevant model parameters are obtained. The model calculation results show that the NRTL model can well correlate the experimental data, which will be helpful to the performance evaluation of absorbents, the selection of new absorbents, and the simulation and optimization of absorption processes.

\section{ACKNOWLEDGEMENT}

This work is supported by the Shandong Natural Science Foundation (Nos. ZR2018BEE024).

\section{REFERENCES}

[1] Kittel J, Fleury E, Vuillemin B, Gonzalez S, Ropital F, Oltra R. (2015). Corrosion in alkanolamine used for acid gas removal: from natural gas processing to $\mathrm{CO}_{2}$ capture. Materials \& Corrosion 63(3): 223-230. https://doi.org/10.1002/maco.201005847

[2] Fei W, Ai N, Chen J. (2005). Capture and separation of greenhouse gas $\mathrm{CO}_{2}$ - challenges and opportunities for separation technology. Chemical Industry and Engineering Progress 24(1): 1-8. https://doi.org/10.16085/j.issn.1000-6613.2005.01.002

[3] Rochelle GT. (2009). Amine scrubbing for $\mathrm{CO}_{2}$ capture. Science 325(5948): 1652-1654. https://doi.org/10.1126/science.1176731

[4] Chang HT, Posey M, Rochelle GT. (1993). Thermodynamics of alkanolamine - water solutions from freezing point measurements. Industrial \& Engineering Chemistry Research 32(10): 2324-2335. https://doi.org/10.1021/ie00022a016
[5] Guan FW, Zhang F, Cao NL, Liu Q, Liu J, Yu SM, Guan HY. (2018). Thermal control design and experimental verification of light off-axis space optical remote sensor in the sun-synchronous orbit. International Journal of Heat and Technology 36(1): 125-132. https://doi.org/10.18280/ijht.360117

[6] Mathonat C, Maham Y, Mather AE, Hepler LG. (1997). Excess molar enthalpies of (water + monoalkanolamine) mixtures at $298.15 \mathrm{~K}$ and $308.15 \mathrm{~K}$. Journal of Chemical \& Engineering Data 42: 993-995. https://doi.org/10.1021/je960304u

[7] Simond MR, Balleratbusserolles K, Coxam JY. (2014). Interactions of Alkanolamines with Water: Excess Enthalpies and Hydrogen Bonding. Journal of Chemical Theory \& Computation 10(6): 2471-2478. https://doi.org/10.1021/ct5002158

[8] Mundhwa M, Henni A. (2007). Molar excess enthalpy $\left(\mathrm{H}^{\mathrm{E}}\right)$ for various \{alkanolamine (1) + water (2) systems at $\mathrm{T}=(298.15,313.15$, and 323.15) K. Journal of Chemical Thermodynamics 39(11): 1439-1451. https://doi.org/10.1016/j.jct.2007.03.010

[9] Wang SH, Luo BC, Zhen DX. (1992). Study on the relationship between the mixed heat and the vapor liquid equilibrium of the two - dimensional poly -ethylene glycol aqueous solution. Journal of Beijing University of Chemical Technology (Natural Science Edition) 19(3): 1-9. https://doi.org/10.13543/j.cnki.bhxbzr. 1992.03.001

[10] Schmidt KAG, Maham Y, Mather AE. (2007). Use of the NRTL equation for simultaneous correlation of vapourliquid equilibria and excess enthalpy appli-cations to aqueous alkanolaminesystems. Journal of Thermal Analysis and Calorimetry 89(1): 61-72. https://doi.org/10.1007/s10973-006-8307-6

[11] Haan AD, Kai F, Haacke M. (1997). Vapor-liquid equilibria and enthalpies of mixing for binary mixtures of n-methylacetamide with aniline, decane, ethylene glycol, naphthalene, phenol, and water. Journal of Chemical \& Engineering Data 42(5): 875-881. https://doi.org/10.1021/je970031i

[12] Renon H, Prausnitz JM. (1968). Local compositions in thermodynamic excess functions for liquid mixtures. Aiche Journal 14(1): 135-144. https://doi.org/10.1002/aic.690140124

[13] Wang H, Lu K, Peng X. (2013). Comparison of Wilson, UNIQUAC and NRTL activity coefficient models for the phase equilibria of systems containing ionic liquids. Journal of Beijing University of Chemical Technology (Natural Science Edition) 40(1): 10-15. https://doi.org/10.13543/j.cnki.bhxbzr.2013.01.015

[14] Touhara H, Okazaki S, Okino F. (1982). Thermodynamic properties of aqueous mixtures of hydrophilic compounds 2. Aminoethanol and its methyl derivatives. Chem. Thermo- Dynamics 14(2): 145-156. https://doi.org/10.1016/0021-9614(82)90026-X

[15] Belabbaci A, Razzouk A, Mokbel I. (2009). Isothermal Vapor-Liquid Equilibria of (Monoethanolamine+Water) and (4-Methylmorpholine+Water) Binary Systems at Several Temperatures. Journal of Chemical \& Engineering Data 54(8): 270-271. https://doi.org/10.1021/je960118o

[16] Park SJ, Shin HY, Min BM. (2009). Vapor-liquid equilibria of water+ monoethanolamine system. Korean Journal of Chemical Engineering 26(1): 189-192. https://doi.org/10.1007/s11814-009-0031-z 
[17] Kim I, Svendsen HF, Børresen E. (2008). Ebulliometric determination of vapor-liquid equilibria for pure water, monoethanolamine, n-methyldiethanolamine, 3-(methylamino)-propylamine, and their binary and ternary solutions. Journal of Chemical \& Engineering Data 53(11): 2521-2531. https://doi.org/10.1021/je800290k

[18] Maham Y, Mather AE, Mathonat C. (2000). Excess properties of (alkyldiethanol- amine $+\mathrm{H}_{2} \mathrm{O}$ ) mixtures at temperatures from (298.15 to 338.15$) \mathrm{K}$. Journal of
Chemical Thermodynamics 32(2): 229-236. https://doi.org/10.1006/jcht.1999.0595

[19] Mukherjee S, Mishra PC, Chaudhuri P, Banerjee G. (2018). Theoretical modeling and optimization of microchannel heat sink cooling with $\mathrm{TiO}_{2}$-water and $\mathrm{ZnO}$ - water nanofluids. International Journal of Heat and Technology 36(1): 165-172. https://doi.org/10.18280/ ijht.360122 